\title{
Occurrence, distribution, and potential influencing factors of sewage sludge components derived from nine full-scale wastewater treatment plants of Beijing, China
}

\author{
Xu Wang ${ }^{1,2, *, * *}$, Meiyan $\mathrm{Li}^{3, * *}$, Junxin $\mathrm{Liu}^{1,2}$, Jiuhui $\mathrm{Qu}{ }^{2}$ \\ 1. Research Center for Eco-Environmental Sciences, Chinese Academy of Sciences, Beijing 100085, China. E-mail: xuwang@rcees.ac.cn \\ 2. State Key Laboratory of Environmental Aquatic Chemistry, Research Center for Eco-Environmental Sciences, Chinese Academy of Sciences, \\ Beijing 100085, China \\ 3. Zhongheronghua Environmental Technology (Beijing) Co. Ltd., Beijing 100085, China
}

\section{A R T I C L E I N F O}

\section{Article history:}

Received 2 October 2015

Revised 5 January 2016

Accepted 6 January 2016

Available online 13 February 2016

\section{Keywords:}

Wastewater treatment plant

Waste activated sludge

Sludge component

Solids retention time

Extracellular polymeric substances

Principal component analysis

\begin{abstract}
A B S T R A C T
Millions of tons of waste activated sludge (WAS) produced from biological wastewater treatment processes cause severe adverse environmental consequences. A better understanding of WAS composition is thus very critical for sustainable sludge management. In this work, the occurrence and distribution of several fundamental sludge constituents were explored in WAS samples from nine full-scale wastewater treatment plants (WWTPs) of Beijing, China. Among all the components investigated, active heterotrophic biomass was dominant in the samples (up to $9478 \mathrm{mg} / \mathrm{L}$ ), followed by endogenous residues $(6736 \mathrm{mg} / \mathrm{L})$, extracellular polymeric substances $(2088 \mathrm{mg} / \mathrm{L})$, and intracellular storage products ( $464 \mathrm{mg} / \mathrm{L}$ ) among others. Moreover, significant differences $(p<0.05)$ were observed in composition profiles of sludge samples among the studied WWTPs. To identify the potential parameters affecting the variable fractions of sludge components, wastewater source as well as design and operational parameters of WWTPs were studied using statistical methods. The findings indicated that the component fraction of sewage sludge depends more on wastewater treatment alternatives than on wastewater characteristics among other parameters. A principal component analysis was conducted, which further indicated that there was a greater proportion of residual inert biomass in the sludge produced by the combined system of the conventional anaerobic/anoxic/oxic process and a membrane bioreactor. Additionally, a much longer solids retention time was also found to influence the sludge composition and induce an increase in both endogenous inert residues and extracellular polymeric substances in the sludge.

(c) 2016 The Research Center for Eco-Environmental Sciences, Chinese Academy of Sciences.
\end{abstract} Published by Elsevier B.V.

\footnotetext{
* Corresponding author.

E-mail addresses: xuwang@rcees.ac.cn (X. Wang), jxliu@rcees.ac.cn (J. Liu).

** The authors contributed equally to this work.
} 


\section{Introduction}

Biological approaches have been extensively used in wastewater treatment plants (WWTPs) worldwide. However, substantial amounts of waste activated sludge (WAS) are generated annually from WWTPs with a marked growth rate (Kroiss, 2004). As estimated, about 8.2 and 3.6 million tons of WAS has been produced in 2009 in the United States and China, respectively (Jiang et al., 2009). Without appropriate disposal at a landfill or direct incineration, this biomass residue will lead to severe environmental and social burdens. Moreover, given the global concerns with respect to energy conservation and resource scarcity in this century, there is increasing awareness that municipal wastes such as WAS should be considered as a valuable resource from which organics, nitrogen, and phosphorus can be harvested to produce energy and raw materials (Wang et al., 2012).

Even if matter is disposed of as a pollutant or recycled as a beneficial resource, sustainable management of WAS still requires more reliable information on the sludge composition because WAS contains a variety of constituents. Furthermore, WAS shows unpredictable sludge characteristics and its component proportion varies with different temporal and spatial contexts, which can have a significant impact on the performance of downstream WAS applications (Jiang et al., 2011; Li et al., 2008; Yin et al., 2013). Additionally, numerous technical issues in handling and disposing WAS arise because of a lack of in-depth understanding of the composition of WAS (Chen et al., 2011; Dursun et al., 2004; Feng et al., 2009). Therefore, it is essential to investigate the composition of WAS derived from numerous WAS samples that account for temporal and geographical factors.

In addition, WAS samples from different WWTPs exhibit varying characteristics and are as unique as fingerprints. At present, numerous alternative combinations of anaerobic/ anoxic/oxic units have been applied in urban wastewater service to prevent aquatic ecosystems and human health from

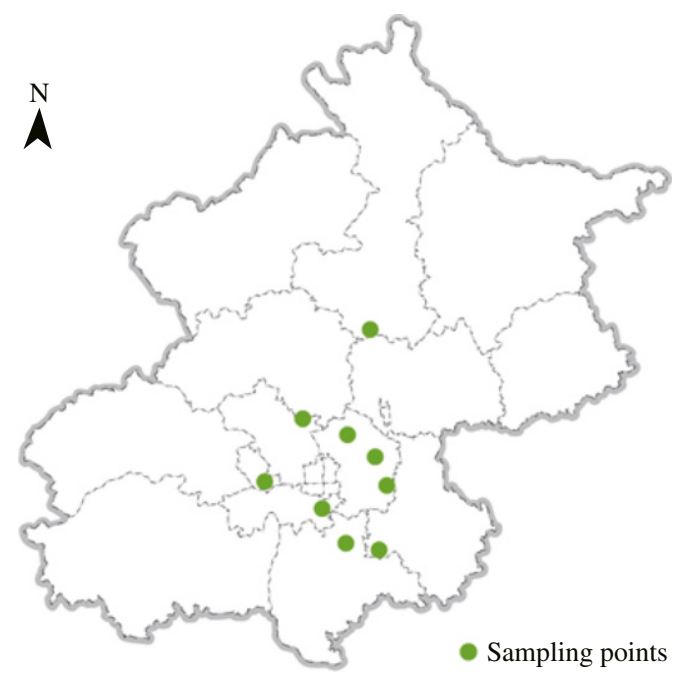

Fig. 1 - Sampling locations of the investigated sludge samples in Beijing, China. severe contaminations (Cassidy and Belia, 2005; Kang et al., 2011; Liu et al., 2010; Zeng et al., 2010). Nevertheless, little research was made on comparing WAS compositions among different wastewater treatment alternatives, and on determining the potential reasons that lead to significant differences among WAS samples by analyzing the influencing factors in the design and operation of different WWTPs.

We thus explored the concentrations and composition profiles of several essential constituents (active microorganisms, residual inert biomass, internal storage products, and extracellular polymeric substances) in the sludge samples collected from nine full-scale municipal WWTPs of Beijing, China. The potential parameters influencing dynamic component factions in WAS were subsequently demonstrated by applying several statistical analysis techniques. Overall, the present work provides beneficial information on origin-specific WAS characteristics, which would be significantly beneficial to decision-makers for pursuing sustainable management of WAS.

\section{Materials and methods}

\subsection{Samples collection}

The sampling map and sites are shown in Fig. 1. All the sludge samples were collected from secondary clarifiers and sealed in different plastic containers, which were freeze-dried immediately, and were then stored at $4^{\circ} \mathrm{C}$ before further analysis. Details of the nine WWTPs are represented in Table 1; these include the service population, treatment capacity, treatment technique, and influent characteristics. It should be noted that even though only nine full-scale WWTPs were included in this work, 11 different biological wastewater treatment alternatives were covered under the investigation as some WWTPs were equipped with two parallel water treatment lines (such as No. 1 WWTP).

\subsection{Assumption and determination of sludge components}

Theoretically, the activated sludge generated from biological wastewater treatment processes consists of four conceptual components (McKinney, 1974): active microbial mass, endogenous mass, inner organic mass, and inert inorganic mass. However, in practice, it is difficult to search appropriate analytical techniques to carry out direct quantifications of these sludge substances without making reasonable assumptions. In the literature ( $\mathrm{Ni}$ et al., 2009), the measurable activated sludge can be expressed by mixed liquid volatile suspended solid (MLVSS) in milligrams of chemical oxygen demand (COD) per liter and is calculated from Eq. (1):

MLVSS $=X_{\mathrm{H}}+X_{I}+X_{E P S}+X_{S T O}$

where the symbols for concentrations of sludge components are denoted as active heterotrophic biomass $\left(X_{H}\right)$, internal storage products $\left(\mathrm{X}_{\mathrm{STO}}\right)$, residual inert biomass $\left(\mathrm{X}_{\mathrm{I}}\right)$, and extracellular polymeric substances (EPS, $X_{E P S}$ ). Thus, these substances $\left(\mathrm{X}_{\mathrm{H}}, \mathrm{X}_{\mathrm{I}}, \mathrm{X}_{\mathrm{EPS}}\right.$, and $\left.\mathrm{X}_{\mathrm{STO}}\right)$ are employed as representative sludge components for further analysis throughout this work. 
Table 1 - Detailed information of the investigated wastewater treatment plants (WWTPs).

\begin{tabular}{|c|c|c|c|c|c|c|}
\hline WWTPs & $\begin{array}{c}\text { Capacity } \\
\left(10^{4} /\left(\mathrm{m}^{3} \cdot \text { day }\right)\right)\end{array}$ & $\begin{array}{c}\text { Population } \\
\left(10^{4} \text { capita/day) }\right.\end{array}$ & Sewage source & $\begin{array}{l}\text { Influent COD } \\
(\mathrm{mg} / \mathrm{L})\end{array}$ & Treatment techniques ${ }^{*}$ & SRT (day) \\
\hline No. 1 & 3.5 & 15 & Domestic 85\%, industrial 15\% & 625.6 & $\mathrm{OD}_{(1)}$ & $11-13$ \\
\hline No. 1 & 3.5 & 15 & Domestic $85 \%$, industrial 15\% & 625.6 & $\mathrm{~A}^{2} / \mathrm{O}+\mathrm{MBR}$ & $23-27$ \\
\hline No. 2 & 20 & 48 & Domestic 70\%, industrial 30\% & 404.9 & $\mathrm{OD}_{(2)}$ & $11-14$ \\
\hline No. 3 & 8 & 30 & Domestic $85 \%$, industrial $15 \%$ & 449.7 & $\mathrm{OD}_{(3)}$ & $11-13$ \\
\hline No. 4 & 5 & 26 & Domestic $20 \%$, industrial $80 \%$ & 533.5 & $\operatorname{CASS}_{(1)}$ & $14-16$ \\
\hline No. 5 & 5 & 23 & Domestic $20 \%$, industrial $80 \%$ & 225.4 & $\operatorname{CASS}_{(2)}$ & $14-16$ \\
\hline No. 6 & 5 & 20 & Domestic $70 \%$, industrial 30\% & 573.5 & $\mathrm{CASS}_{(3)}$ & $14-16$ \\
\hline No. 7 & 20 & 40.7 & Domestic $85 \%$, industrial $15 \%$ & 531.2 & Inverted $\mathrm{A}^{2} / \mathrm{O}$ & $8-10$ \\
\hline No. 7 & 20 & 40.7 & Domestic $85 \%$, industrial $15 \%$ & 531.2 & $\mathrm{~A}^{2} / \mathrm{O}_{(1)}$ & $13-15$ \\
\hline No. 8 & 60 & 206 & Domestic $85 \%$, industrial $15 \%$ & 543.5 & $\mathrm{~A}^{2} / \mathrm{O}_{(2)}$ & $11-12$ \\
\hline No. 9 & 100 & 15 & Domestic 50\%, industrial 50\% & 410.0 & CAS & $13-17$ \\
\hline \multicolumn{7}{|c|}{$\begin{array}{l}\text { SRT: Solids retention time; WWTPs: wastewater treatment plants; COD: chemical oxygen demand; SRT: solids retention time; OD: oxidation } \\
\text { ditch; } \mathrm{A}^{2} / O+\mathrm{MBR} \text { : combination of typical } \mathrm{A}^{2} / \mathrm{O} \text { process and membrane bioreactor; CASS: cyclic activated sludge system; CAS: conventional } \\
\text { activated sludge; } \mathrm{A}^{2} / \mathrm{O} \text { : conventional anaerobic/anoxic/oxic process; inverted } \mathrm{A}^{2} / \mathrm{O} \text { : inverted anaerobic/anoxic/oxic. } \\
{ }^{*} \text { Subscripts represent the alternative transformations of the treatment technique. }\end{array}$} \\
\hline
\end{tabular}

Subsequently, the determinations of COD and MLVSS were carried out following Standard Methods (APHA, 1995), whereas a batch approach was used to quantify the concentration of $\mathrm{X}_{\mathrm{H}}$ (Kappeler and Gujer, 1992). The EPS of the sludge samples were extracted using the $\mathrm{NaOH}$ method, as described in a previous study (Liu and Fang, 2002). As the main components of EPS, the measurements of the soluble protein and polysaccharides used typical approaches (Dubois et al., 1956; Frolund et al., 1995); the sum of soluble protein and polysaccharides was then used to represent EPS. For extraction (Pratt et al., 2004) and determination (Ni et al., 2010) of $\mathrm{X}_{\mathrm{STO}}$, samples of $10 \mathrm{~mL}$ were centrifuged at $4000 \mathrm{r} / \mathrm{min}$ for $10 \mathrm{~min}$ and decanted, and the biomass pellet was freeze-dried at $54^{\circ} \mathrm{C}$ to remove the moisture content. The solid material was suspended in $2 \mathrm{~mL}$ of acidic methanol solution $\left(3 \% \mathrm{H}_{2} \mathrm{SO}_{4}\right)$ and $2 \mathrm{~mL}$ of chloroform. The glass tube was screwed tightly and heated to $100^{\circ} \mathrm{C}$ for $6 \mathrm{hr}$. After cooling, $1 \mathrm{~mL}$ of Milli-Q water was added to the tube and the resultant mixture was shaken vigorously for $10 \mathrm{~min}$. When the phases were separated, $1 \mathrm{~mL}$ of the bottom organic layer was removed to the gas chromatography (GC) vials for $\mathrm{X}_{\mathrm{STO}}$ determination. After the GC analysis, $X_{\text {STO }}$ measured in this work was proven mainly to be poly-hydroxybutyrate. The concentration of $X_{I}$ was assumed to be the difference between MLVSS and the sum of $\mathrm{X}_{\mathrm{H}}, \mathrm{X}_{\mathrm{EPS}}$, and $\mathrm{X}_{\mathrm{STO}}$ (Ni et al., 2009).

\subsection{Statistical analysis techniques}

Herein, statistical analyses were conducted by using the statistical software SPSS 19.0. Spearman correlation analysis (Shin et al., 2011) was employed to evaluate the correlations among the focused constituents in sludge samples. Comparisons of constituent proportions were performed utilizing the two-sample Kolmogorov-Smirnov nonparametric test (Qin and Zhang, 1997). For all comparisons in this work, $p<0.05$ was considered significant. In addition, principal component analysis (PCA) on the analytical data was executed to attain a visual illustration of the main characteristics and the principal components (PCs) for eigenvalues greater than 1 (Scholkopf et al., 1998).

\section{Results and discussion}

\subsection{Concentrations and component proportions of the WAS samples}

Initially, the concentration levels of the individual sludge components of the sludge samples were presented by box-and-whisker plots, as shown in Fig. 2. Specifically, the concentrations of $X_{\mathrm{H}}, \mathrm{X}_{\mathrm{I}}, \mathrm{X}_{\mathrm{EPS}}$, and $\mathrm{X}_{\mathrm{STO}}$ in the WAS samples were in the range of 558.8-9478.0 mg/L (mean: $3497.0 \mathrm{mg} / \mathrm{L}$ ),

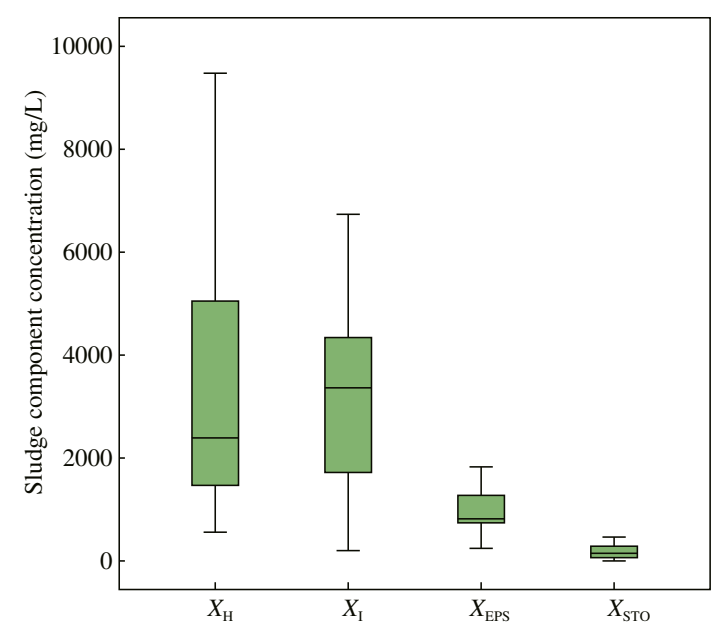

Fig. 2 - Box-and-whisker plots of the four investigated components in sludge samples collected from nine WWTPs in Beijing. The horizontal black line in the box represents the median value, and the lower and upper edges of the box mark the 25th and 75th percentiles. The whiskers extending from the box show the highest and lowest values. The singular values are represented by the cycle symbol, which were beyond the 150th percentile of the difference between 25th and 75th percentiles. 
Table 2-Spearman's rank correlations among $X_{H}, X_{I}$, $\mathbf{X}_{\mathrm{EPS}}$, and $\mathrm{X}_{\mathrm{STo}}$ in the WAS samples.

\begin{tabular}{lllll} 
& \multicolumn{1}{c}{$\mathrm{X}_{\mathrm{H}}$} & \multicolumn{1}{c}{$\mathrm{X}_{\mathrm{I}}$} & \multicolumn{1}{c}{$\mathrm{X}_{\mathrm{EPS}}$} & $\mathrm{X}_{\mathrm{STO}}$ \\
\hline $\mathrm{X}_{\mathrm{H}}$ & 1 & & \\
$\mathrm{X}_{\mathrm{I}}$ & 0.270 & 1 & & \\
$\mathrm{X}_{\mathrm{EPS}}$ & $0.554^{* *}$ & 0.390 & 1 & \\
$\mathrm{X}_{\mathrm{STO}}$ & $0.435^{*}$ & $0.658^{* *}$ & $0.639^{* *}$ & 1 \\
\hline \multicolumn{3}{l}{ WAS: waste activated sludge. } \\
Correlation is significant at the 0.01 level (2-tailed). \\
Correlation is significant at the 0.05 level (2-tailed). \\
\hline
\end{tabular}

200.6-6736.0 mg/L (mean: $3239.6 \mathrm{mg} / \mathrm{L}), \quad 244.4-2088.0 \mathrm{mg} / \mathrm{L}$ (mean: $980.9 \mathrm{mg} / \mathrm{L}$ ), and 0-464.0 mg/L (mean: $175.9 \mathrm{mg} / \mathrm{L}$ ), respectively. In addition, Spearman's correlation analysis, as represented in Table 2, showed significant correlations $(p<0.05)$ among the constituents (expect $X_{H}$ and $X_{I}$, as well as $X_{\text {EPS }}$ and $X_{I}$ ), which suggested common sources and similar environmental fates of sludge components generated from the WWTPs in this study. The component proportion profiles of $X_{H}, X_{I}, X_{E P S}$, and $X_{\mathrm{STO}}$ in the samples derived from 11 different biological wastewater treatment alternatives are presented in Fig. 3. The proportions of the four sludge components were found to vary significantly with various sewage sources and districts of the alternative wastewater treatment processes $(p<0.05)$.

To further evaluate the potential factors influencing the component proportions in WAS, related information, such as wastewater sources (domestic, industrial, or combined), as well as design parameters and operation conditions of the WWTPs (i.e., treatment capacity, service population, and wastewater treatment alternative) were investigated, and are discussed in subsequent sections.

\subsection{Factors causing variable component proportions in WAS samples}

\subsubsection{Treatment capacity and service population}

Serving as a significant precursor to the design and operation of WWTPs, treatment capacity and service population were investigated to evaluate the components of WAS. Specifically, the Spearman's correlation analysis showed that the proportions of the investigated components in the sludge samples have no significant relationship with individual parameters $(p>0.05)$.

\subsubsection{Sewage source}

Generally, municipal sewage and industrial wastewater were the essential sources of WWTPs. The WWTPs investigated in this work were all fed with a combination of municipal sewage and industrial wastewater. Among them, seven WWTPs were driven with $70 \%-85 \%$ of domestic sewage, and the remaining WWTPs were fed with $>50 \%$ of industrial wastewater (Table 1). As represented in Fig. 3, the top two highest active heterotrophic biomass $\left(\mathrm{X}_{\mathrm{H}}\right)$ fractions $(77.3 \%$ and $57.7 \%$, respectively) in the samples were detected in WWTP nos. 1 and 8 (i.e., $\mathrm{OD}_{(1)}$ and $\mathrm{A}^{2} /$ $\mathrm{O}_{(2)}$ respectively), which were both fed with a greater fraction (85\%) of domestic wastewater. Since the industrial wastewater investigated herein was mainly derived from electronics factories and thus contained a variety of toxic substances, it was evident that a lower fraction of industrial waste streams would enhance the probability of preventing active microorganisms from chemical toxicity. Further, the proportion of EPS detected in WWTPs fed with a larger fraction of domestic sewage was also much higher than those in WWTPs driven with greater industrial waste streams. Thus, the proportions of microorganism-related substances in sludge probably associated with the different sources of the sewage in the explored WWTPs.

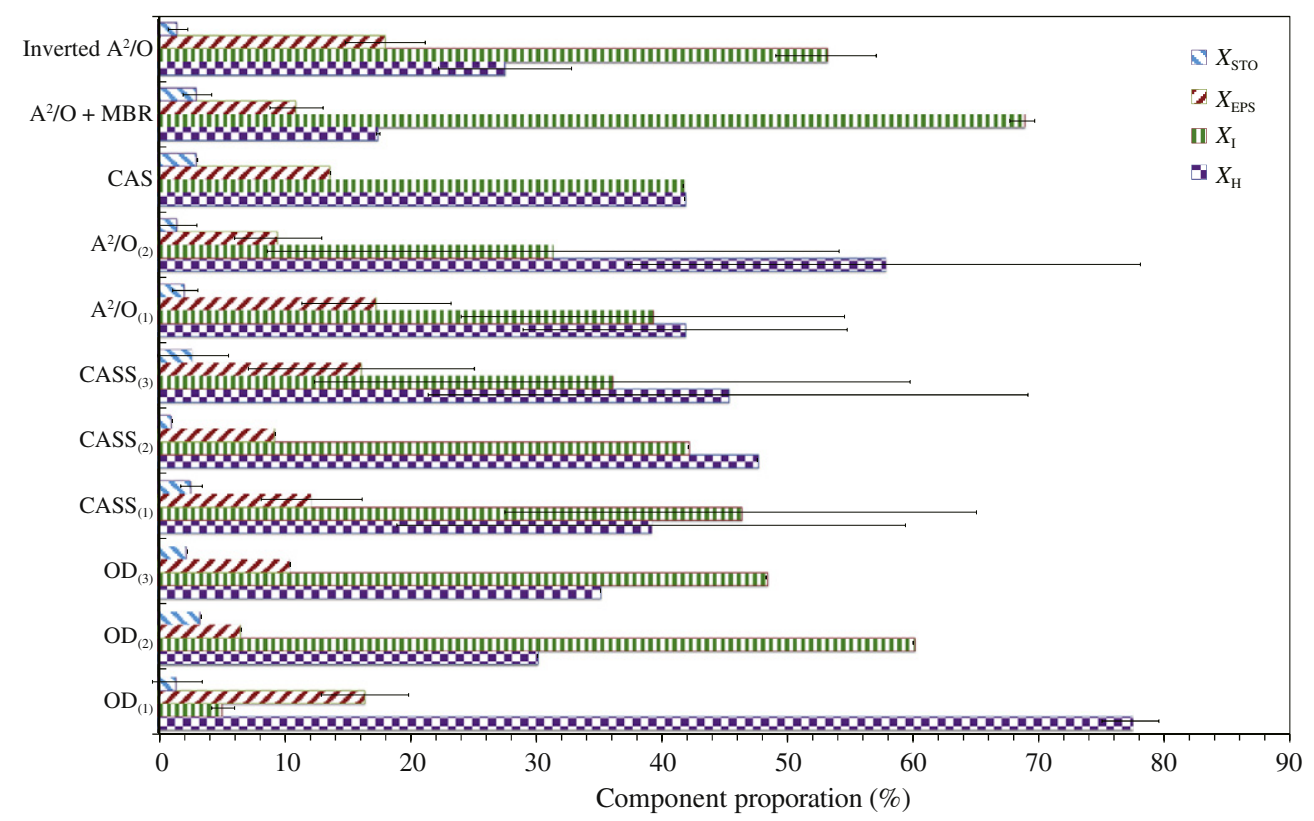

Fig. 3 - Statistical proportions of the four investigated components in sludge samples derived from 11 different biological wastewater treatment alternatives. 

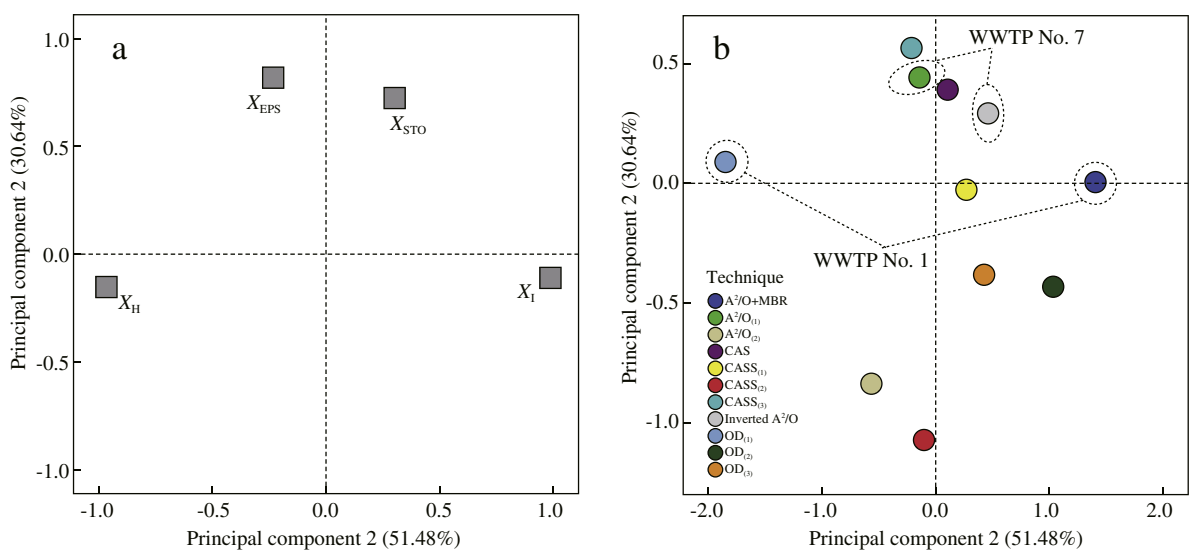

Fig. 4 - The loading (a) and score (b) plots of PCA by the database of the four investigated constituents in the WAS samples. PCA: principal component analysis.

\subsubsection{Biological wastewater treatment alternative}

To date, numerous biological wastewater treatment alternatives have been applied extensively worldwide owing to their reasonable operating and maintenance costs. Nevertheless, there have been few studies showing the component proportions of $X_{H}, X_{I}$, $X_{\mathrm{EPS}}$, and $X_{\mathrm{STO}}$ in WAS as relevant to the type of biological wastewater treatment technique. Table 1 summarizes the 11 different biological wastewater treatment alternatives of the nine full-scale WWTPs investigated. These were mainly divided into conventional activated sludge (CAS) process, cyclic activated sludge system (CASS), oxidation ditch (OD), conventional anaerobic/anoxic/oxic $\left(\mathrm{A}^{2} / \mathrm{O}\right)$ process, inverted anaerobic/anoxic/oxic (inverted $\mathrm{A}^{2} / \mathrm{O}$ ), and a combination of typical $\mathrm{A}^{2} / \mathrm{O}$ process and membrane bioreactor $\left(A^{2} / O+M B R\right)$. In the present work, the relation between treatment techniques and the proportions of sludge components was studied using a PCA approach.

The varimax rotation in the present work reduced the four variables to two PCs with eigenvalues greater than 1, which represent $82.12 \%$ of the cumulative variances. Fig. 4 portrays the loading and score plots of the two PCs. As represented in Fig. 4a, PC1 accounted for $51.48 \%$ of the total variance and illustrates strong positive loadings on residual inert biomass $\left(\mathrm{X}_{\mathrm{I}}\right)$, whereas PC2 accounted for as much as $30.64 \%$ of the total variance and shows moderately positive loadings for the extracellular polymeric substances $\left(X_{\mathrm{EPS}}\right)$. Furthermore, the score plots of PCA in Fig. $4 \mathrm{~b}$ were grouped by wastewater treatment alternatives to visualize their potential connections. The average loading scores of PC1 and PC2 in the sludge samples collected from the WWTPs were respectively in the order of " $A^{2} / O+$ MBR $>$ Inverted $A^{2} /$ $\mathrm{O}>\mathrm{CAS}>\mathrm{CASS}>\mathrm{OD}>\mathrm{A}^{2} / \mathrm{O}$ " and "CAS $>$ Inverted $\mathrm{A}^{2} / \mathrm{O}>\mathrm{A}^{2} /$ $\mathrm{O}+\mathrm{MBR}>\mathrm{CASS}>\mathrm{A}^{2} / \mathrm{O}>\mathrm{OD}$ ". This result indicates that the fractions of sludge constituents could vary significantly based on the wastewater treatment alternatives. For example, the PCA outcomes illustrate that $\mathrm{A}_{2} / \mathrm{O}+\mathrm{MBR}$ has markedly the highest loading scores of PC1 in the component plot (Fig. 4b), suggesting a greater proportion of residual inert biomass in the sludge produced by the $\mathrm{A}^{2} / \mathrm{O}+\mathrm{MBR}$ plant. Biological wastewater treatment takes one of the two general forms: suspended growth systems (e.g., CAS, CASS, OD, and $\mathrm{A}^{2} / \mathrm{O}$ ) or attached growth systems (e.g., trickling filters). Depending on the operational conditions, both could function differently. For example, the critical operational variable for suspended growth system is the solids retention time (SRT), and a longer SRT is able to strengthen endogenous metabolisms, which thereby lead to increased residual inert substances in sludge (Huang et al., 2001; Ouyang and Liu, 2009; Teck et al., 2009). Thus, it could be understandable that a greater fraction of residual inert biomass was presented in the $A^{2} / O+M B R$ sludge, since MBRs are similar to suspended growth systems that use sedimentation for biomass separation, but can be operated at a much higher SRT (Yang et al., 2006). In the subsequent analysis, $\mathrm{OD}_{(1)}$ and $\mathrm{A}_{2} / \mathrm{O}+\mathrm{MBR}$ systems which operated with very different SRTs (11-13 days and 23-27 days, respectively) in spite of feeding with same influent wastewater (WWTP no. 1), exhibited markedly different fractions of nonbiodegradable endogenous residues in their sludge (see PC1 of Fig. $4 b)$, and a greater fraction of residues was represented in the sludge of the latter system. In this regard, it was evident that a longer SRT can affect and improve the levels of residual inert substances in sludge.

On the other hand, the EPS content in sludge was also found to be relevant with respect to the biological treatment techniques (PC2 of Fig. 4b). Literature on the effect of operational parameters such as SRT on EPS generation is conflicting. A few studies have reported higher EPS concentrations at longer SRTs (Badireddy et al., 2010; $\mathrm{Ng}$ and Hermanowicz, 2005), whereas others have observed lower concentrations at longer SRTs (Ahmed et al., 2007; Masse et al., 2006). In additional literature the EPS content was found to be independent of the SRT (Sponza, 2002). In the present study, it was found that the SRT would affect the EPS proportion in sludge, which was derived from the comparison of the $A_{2} / O_{(1)}$ and inverted $A_{2} / O$ processes in WWTP no. 7 (Fig. 4b, PC2), suggesting that a longer SRT induced an increase in the EPS fraction in sludge. Actually, the EPS fraction is growth-related, and is determined by a dynamic balance between microbial production and subsequent degradation (Faust et al., 2014). At short SRTs, the microbial activity is strong in the bioreactor, and much EPS could be produced by microbes under substrate utilization, whereas at long SRTs, microbes are in the endogenous respiration or decline period and proteins are released from the microorganisms into the network structure of EPS. 
Overall, the fractions of residual inert substances and EPS in sludge were found to be relevant with biological wastewater treatment processes, and were significantly impacted by operational variables such as SRT. However, further comparative studies with a wider coverage of treatment approaches including suspended and attached growth systems are essential to decipher the further relationship between biological treatment methods and sludge composition. Additionally, elaborate explorations on a plant are needed to verify whether considerable variations really occur in the inert residues and EPS collected from the same system but sampled at different SRTs.

\section{Conclusions}

In this, a total of four essential components including active heterotrophic biomass, internal storage products, residual biomass, and extracellular polymeric substances in WAS samples were collected from nine domestic WWTPs which includes 11 alternative activated sludge processes in Beijing, China. The sludge samples obtained from the different WWTPs showed variable concentrations and composition profiles of the studied sludge components, highlighting the significance of exploring factors that cause such significant differences. The results of several statistical analysis techniques revealed that the fraction level of the sludge constituents was associated with the composition of sewage source, and particularly the treatment techniques of the studied WWTPs. Furthermore, SRT was found to be an important parameter as it was able to influence the levels of inert residues and EPS in sludge, and a longer SRT could induce increases in unbiodegradable endogenous residues and EPS contents in sludge.

\section{Acknowledgments}

This work was supported by the National Natural Science Foundation of China (Nos. 51408589 and 51138009), State Key Joint Laboratory of Environment Simulation and Pollution Control of China (Research Center for Eco-Environmental Sciences, Chinese Academy of Sciences, No. 14Z03ESPCR), and Youth Innovation Promotion Association of the Chinese Academy of Sciences.

\section{R E F E R E N C E S}

Ahmed, Z., Cho, J., Lim, B.-R., Song, K.-G., Ahn, K.-H., 2007. Effects of sludge retention time on membrane fouling and microbial community structure in a membrane bioreactor. J. Membr. Sci. 287 (2), 211-218.

APHA, 1995. Standard Methods for the Examination of Water and Wastewater. American Public Health Association, Washington, DC, USA.

Badireddy, A.R., Chellam, S., Gassman, P.L., Engelhard, M.H., Lea, A.S., Rosso, K.M., 2010. Role of extracellular polymeric substances in bioflocculation of activated sludge microorganisms under glucose-controlled conditions. Water Res. 44 (15), 4505-4516.
Cassidy, D.P., Belia, E., 2005. Nitrogen and phosphorus removal from an abattoir wastewater in a SBR with aerobic granular sludge. Water Res. 39 (19), 4817-4823.

Chen, K., Lei, H.Y., Li, Y.J., Li, H.L., Zhang, X.H., Yao, C., 2011. Physical and chemical characteristics of waste activated sludge treated with electric field. Process Saf. Environ. 89 (5), 327-333.

Dubois, M., Gilles, K.A., Hamilton, J.K., Rebers, P.A., Smith, F., 1956. Colorimetric method for determination of sugars and related substances. Anal. Chem. 28 (3), 350-356.

Dursun, D., Ayol, A., Dentel, S.K., 2004. Physical characteristics of a waste activated sludge: conditioning responses and correlations with a synthetic surrogate. Water Sci. Technol. 50 (9), 129-136.

Faust, L., Temmink, H., Zwijnenburg, A., Kemperman, A.J.B., Rijnaarts, H.H.M., 2014. High loaded MBRs for organic matter recovery from sewage: effect of solids retention time on bioflocculation and on the role of extracellular polymers. Water Res. 56, 258-266.

Feng, X., Lei, H.Y., Deng, J.C., Yu, Q., Li, H.L., 2009. Physical and chemical characteristics of waste activated sludge treated ultrasonically. Chem. Eng. Process. 48 (1), 187-194.

Frolund, B., Griebe, T., Nielsen, P.H., 1995. Enzymatic-activity in the activated-sludge floc matrix. Appl. Microbiol. Biotechnol. 43 (4), 755-761.

Huang, X., Gui, P., Qian, Y., 2001. Effect of sludge retention time on microbial behaviour in a submerged membrane bioreactor. Process Biochem. 36 (10), 1001-1006.

Jiang, J.Q., Zhao, Q.L., Wei, L.L., Wang, K., Lee, D.J., 2011. Degradation and characteristic changes of organic matter in sewage sludge using microbial fuel cell with ultrasound pretreatment. Bioresour. Technol. 102 (1), 272-277.

Jiang, J.Q., Zhao, Q.L., Zhang, J.N., Zhang, G.D., Lee, D.J., 2009. Electricity generation from bio-treatment of sewage sludge with microbial fuel cell. Bioresour. Technol. 100 (23), 5808-5812.

Kang, X.S., Liu, C.Q., Zhang, B., Bi, X.J., Zhang, F., Cheng, L.H., 2011. Application of reversed $A(2) / O$ process on removing nitrogen and phosphorus from municipal wastewater in China. Water Sci. Technol. 63 (10), 2138-2142.

Kappeler, J., Gujer, W., 1992. Estimation of kinetic-parameters of heterotrophic biomass under aerobic conditions and characterization of waste-water for activated-sludge modeling. Water Sci. Technol. 25 (6), 125-139.

Kroiss, H., 2004. What is the potential for utilizing the resources in sludge? Water Sci. Technol. 49 (10), 1-10.

Li, R.Y., Zhang, T., Fang, H.H.P., 2008. Characteristics of a phototrophic sludge producing hydrogen from acetate and butyrate. Int. J. Hydrog. Energy 33 (9), 2147-2155.

Liu, H., Fang, H.H.P., 2002. Extraction of extracellular polymeric substances (EPS) of sludges. J. Biotechnol. 95 (3), 249-256.

Liu, Y.C., Shi, H.C., Xia, L., Shi, H.M., Shen, T.G., Wang, Z.Q., Wang, G., Wang, Y.Z., 2010. Study of operational conditions of simultaneous nitrification and denitrification in a Carrousel oxidation ditch for domestic wastewater treatment. Bioresour. Technol. 101 (3), 901-906.

Masse, A., Sperandio, M., Cabassud, C., 2006. Comparison of sludge characteristics and performance of a submerged membrane bioreactor and an activated sludge process at high solids retention time. Water Res. 40 (12), 2405-2415.

McKinney, R.E., 1974. Design and operation model for complete mixing activated-sludge system. Biotechnol. Bioeng. 16 (6), 703-722.

Ng, H.Y., Hermanowicz, S.W., 2005. Membrane bioreactor operation at short solids retention times: performance and biomass characteristics. Water Res. 39 (6), 981-992.

Ni, B.J., Fang, F., Rittmann, B.E., Yu, H.Q., 2009. Modeling microbial products in activated sludge under feast-famine conditions. Environ. Sci. Technol. 43 (7), 2489-2497. 
Ni, B.J., Rittmann, B.E., Fang, F., Xu, J.A., Yu, H.Q., 2010. Long-term formation of microbial products in a sequencing batch reactor. Water Res. 44 (13), 3787-3796.

Ouyang, K., Liu, J.X., 2009. Effect of sludge retention time on sludge characteristics and membrane fouling of membrane bioreactor. J. Environ. Sci. (China) 21 (10), 1329-1335.

Pratt, S., Yuan, Z.G., Keller, J., 2004. Modeling aerobic carbon oxidation and storage by integrating respirometric, titrimetric, and off-gas $\mathrm{CO}_{2}$ measurements. Biotechnol. Bioeng. 88 (2), 135-147.

Qin, J., Zhang, B., 1997. A goodness-of-fit test for logistic regression models based on case-control data. Biometrika 84 (3), 609-618

Scholkopf, B., Smola, A., Muller, K.R., 1998. Nonlinear component analysis as a kernel eigenvalue problem. Neural Comput. 10 (5), 1299-1319.

Shin, H.M., Vieira, V.M., Ryan, P.B., Detwiler, R., Sanders, B., Steenland, K., Bartell, S.M., 2011. Environmental fate and transport modeling for perfluorooctanoic acid emitted from the Washington Works facility in West Virginia. Environ. Sci. Technol. 45 (4), 1435-1442.

Sponza, D.T., 2002. Extracellular polymer substances and physicochemical properties of flocs in steady- and unsteady-state activated sludge systems. Process Biochem. 37 (9), 983-998.

Teck, H.C., Loong, K.S., Sun, D.D., Leckie, J.O., 2009. Influence of a prolonged solid retention time environment on nitrification/ denitrification and sludge production in a submerged membrane bioreactor. Desalination 245 (1-3), 28-43.

Wang, X., Liu, J.X., Ren, N.Q., Yu, H.Q., Lee, D.J., Guo, X.S., 2012. Assessment of multiple sustainability demands for wastewater treatment alternatives: a refined evaluation scheme and case study. Environ. Sci. Technol. 46 (10), 5542-5549.

Yang, W.B., Cicek, N., Ilg, J., 2006. State-of-the-art of membrane bioreactors: worldwide research and commercial applications in North America. J. Membr. Sci. 270 (1-2), 201-211.

Yin, F.B., Li, Z.F., Ma, H.H., Xun, L., Bai, X.F., Yin, Y., 2013. Experimental study on rheological characteristics of high solid content sludge and it is mesophilic anaerobic digestion. J. Renewable Sustainable Energy 5 (4).

Zeng, W., Li, L., Yang, Y.Y., Wang, S.Y., Peng, Y.Z., 2010. Nitritation and denitritation of domestic wastewater using a continuous anaerobic-anoxic-aerobic (A(2)O) process at ambient temperatures. Bioresour. Technol. 101 (21), 8074-8082. 